\section{The use of DRS and GC to study the effects of ionizing radiation on paper artifacts}

Wojciech Gluszewski, Bartłomiej Boruc, Hieronim Kubera, Dinara Abbasowa

\begin{abstract}
Radiation preservation of objects of historical significance is an interesting proposition for museums, archives, libraries and private collectors. In this paper, we have limited ourselves to studying the effects of ionizing radiation on the paper. The radiation resistance of various grades of paper was examined in INCT. Irradiations were done by electron beam $(10 \mathrm{MeV}, 10 \mathrm{~kW})$ and by gamma radiation $(7 \mathrm{kG} / \mathrm{h})$, for the purpose of comparison. Yields of hydrogen and absorption of oxygen were determined by gas chromatography (GC). For this purpose, the first time in an original way was used diffuse reflection spectroscopy (DRS). Described as the dose, dose rate, and lignin were found to affect degradation processes of cellulose. Examined the protective effect of lignin in the process of radiation degradation of paper. Proposed research methodology can be successfully applied to study other materials relevant to the conservation of works of art.
\end{abstract}

Key words: electron beam (EB) $\bullet$ disinfection $\bullet$ disinfestation $\bullet$ diffuse reflection spectrometry (DRS) paper - gas chromatography (GC)

\section{W. Głuszewski ${ }^{凶}$}

Institute of Nuclear Chemistry and Technology,

16 Dorodna Str., 03-195 Warsaw, Poland,

Tel.: +48 22504 1288, Fax: +48 22811 1532,

E-mail:w.gluszewski@ichtj.waw.pl

B. Boruc, H. Kubera

Department of Printing Techniques,

Institute of Mechanics and Printing,

Faculty of Production Engineering,

Warsaw University of Technology,

85 Narbutta Str., 02-524 Warsaw, Poland

\section{Abbasowa}

Institute of Geology of the Polish Academy of Sciences, 51/55 Twarda Str., 00-818 Warsaw, Poland and Institute of Radiation Problems of AzNAS, Azerbaijan

Received: 21 October 2014

Accepted: 20 May 2015

\section{Introduction}

Problem of radiolysis of paper may be interesting from the point of view of old books, documents and other articles made from cellulose (bags, suitcases).

Biodeterioration is one of the most significant sources of paper degradation [1-3]. Librarian archives often are attacked by insects, fungi, actinomycetes, and bacteria, when stored in improper conditions [4]. Numerous investigations report on different species of microorganisms identified on paper files and books [5] that feed on cellulose and cause biological coating masking surface properties, increased leaching of additives and monomers that are used as nutrients, production of metabolites, enzymatic attack, physical penetration and disruption, water accumulation, excretion of pigments. The effect of biological aggressors is found to depend on environmental conditions, as well as on substrate composition [6]. Although that the librarian archives in tropical and subtropical regions are reported to be more susceptible to biological aggressors, due to the high ambient temperature and relative humidity [7], the problems of biodeterioration of books and archive documents at temperate climate still remains and cannot be neglected. The negative effects of biological agents on papers in- 
clude not only cellulose degradation and damage but also can seriously jeopardize the health of librarians and restaurateurs, provoking allergies, respiratory diseases etc. Radiation processing technology has been proved to be efficient method for insect eradication and disinfection of biodeteriorated books and documents [8-11]. Both gamma and electron beam (EB) irradiation have been successfully applied to inactivate biological aggressors on different materials $[12,13]$. Gamma irradiation is considered as an especially efficient method for disinfestation due to its high penetration, reliability, lack of harmful residues and no need to use toxic chemical fumigants. EB processing was put forth as a very effective method for biological decontamination because it can produce ions, electrons and free radicals at any temperature in different materials [14]. It performs best when used on low-density, uniformly packaged products. EB irradiation was found to have smaller effect of oxidation and postradiation degradation of the irradiated material, compared to gamma irradiation [15].

Although radiation processing for disinfestations of archives has advantages, this technique is not regularly well accepted and routinely used in many countries with industrial irradiators. The main hesitations of librarians, restorators and conservators are provoked by the possible degradation effects of the ionizing radiation on the paper. Therefore, studies on the effects of ionizing radiation on library, archives from Sofia University in Bulgaria were initiated. The biocide effects of the gamma irradiation on different microbial populations, found on biodeteriorated books were investigated. Paper samples, taken from different issues, published in the period from 1896 to 1965 years were irradiated with 4, 10 and $20 \mathrm{kGy}$. The obtained results showed that $4 \mathrm{kGy}$ have caused a significant decrease of the total number of microorganisms in all the paper samples. Similar data were obtained after $10 \mathrm{kGy}$. Only single actinomycetes strain survived the dose of $20 \mathrm{kGy}$ [16].

One of the objectives of the work is to draw attention to the possibility of using the DRS method in studying the effect of ionizing radiation on the paper. We wanted especially to show the way to study the possible chain degradation processes of paper (in the aging process). This problem is often raised by art conservators and not fully understood. Little is also quantitative data on the protective effect of lignin on the degradation process.

\section{The protective effect}

Unique for radiation chemistry are primary phenomena. Absorption of ionizing radiation causes the detachment of electrons that travel to places of energetically preferential sites, for example, positive holes from previous ionizations or places where two chains are close to one another. The positive holes are also wandering along the chains, also to energetically preferable sites, other than those for electrons. Formation of excited states (as a result of electron capture by the hole) also takes place. All these phenomena, precedes the creation of a macroradicals. Translation of reactive species plays an important role in protective phenomena, if aromatic compounds are present. In event of a paper is the addition of aromatic lignin.

\section{Materials}

Radiation resistance of manuscripts depends on the chemical composition of the paper (content: cellulose and lignin). Studies were conducted on two kinds of paper: almost pure cellulose and newsprint with high lignin content. An attempt was made to assess the protective effect of addition of aromatic lignin.

\section{Irradiations}

Irradiations were done by EB and gamma radiation for the purpose of comparison. Different dose rates and doses were applied. Used gamma radiation sources were produced in India with dose rate $7.0 \mathrm{kGy} / \mathrm{h}$. The EB accelerator Elektronika 10/10 was used, producing scanned beam of electrons of energy of $10 \mathrm{MeV}$ and of $9 \mathrm{~kW}$ power with the possibility of changing the dose rate by controlling the speed of the conveyer. The dose rates in accelerator irradiations were $18000 \mathrm{kGy} / \mathrm{h}$. Samples were irradiated in air, closed vessels with gas phase subjected to gas chromatographic analysis, at room temperature. The use of different dose rates allowed to describe the impact of diffusion of oxygen on degradation processes and consequently on the properties of processed papers. The sample was irradiated with doses of 5, 10, 20 and $50 \mathrm{kGy}$. Intentionally used were doses much higher than used for typical radiation disinfection, in order to observe the process of postradiation oxidation.

\section{Gas chromatography}

Yields of hydrogen and absorption of oxygen were determined by gas chromatography. Gas chromatograph type GC 2014 by Shimadzu, with thermal conductivity detector, column packed with molecular sieves 5A was applied for analyses of gaseous products formed in samples submitted for the electron irradiation (hydrogen and carbon monoxide) as well as loss of oxygen in the atmosphere surrounding the sample in the irradiation vessel. The chromatographic system was working at $100^{\circ} \mathrm{C}$, the column was kept at $40^{\circ} \mathrm{C}$ and the detector at $120^{\circ} \mathrm{C}$. The rate of flow of carrier gas was $10 \mathrm{ml} / \mathrm{min}$.

\section{Diffuse reflection spectroscopy}

One of advantages of DRS is the possibility to investigate polymers in any shape. The principle of measurement consists of directing the beam of analyzing light on the surface of the sample. Part 
Table 1. Values radiation efficiency of hydrogen evolution and oxygen uptake for cellulose and cellulose + lignin, for different dose rate

\begin{tabular}{lcccc}
\hline & \multicolumn{2}{c}{ EB $(18000 \mathrm{kGy} / \mathrm{h})$} & \multicolumn{2}{c}{$\gamma(7 \mathrm{kGy} / \mathrm{h})$} \\
\cline { 2 - 5 } & Celulose & Celulose + lignine & Celulose & Celulose + lignine \\
\hline $\mathrm{GH}_{2}[\mu \mathrm{mol} / \mathrm{J}]$ & 0.334 & 0.211 & 0.329 & 0.206 \\
$-\mathrm{GO}_{2}[\mu \mathrm{mol} / \mathrm{J}]$ & 0.942 & 0.532 & 1.720 & 0.842 \\
\hline
\end{tabular}

EB: electron beam.

of light is reflected back unchanged, but another is bent into the sample and after inside reflections leaves the sample with spectral information about compounds formed as a result of irradiation and/or compounds present before and destroyed. In our investigations, the spectrophotometer JASCO V-670 equipped with reflection device was used.

\section{Paper aging}

An interesting question is whether the irradiation process starts the postradiation chain of oxidation of paper. For this purpose, measured were DRS after irradiation and aging of the paper. DRS spectra obtained relative to nonirradiated sample and the nonirradiated and aged. Samples were subjected to atmosphere for 24 months and then annealed at a temperature of $70^{\circ} \mathrm{C}$ for 196 hours.

\section{Results}

Table 1 summarizes the values of radiation efficiency of hydrogen evolution and oxygen uptake for different dose rates. Given are values of radiation efficiency for a range of doses from 5 to $25 \mathrm{kGy}$. The radiation-emitted hydrogen quantity hardly changes with the power of the dose. In contrast, the volume of oxygen absorbed is significantly increased with the reduction of the dose. The results show that the use of EB (high dose rate) reduces the efficiency of oxidation. A similar effect was observed in the DRS spectra, which cannot be found in the article. It must be assumed that prolonged irradiation facilitates the diffusion of oxygen into the interior of the paper.

With the dose of radiation is noted an increase in the bands corresponding to the products of oxidation (Fig. 1). Several bands of absorption were identified. The band around $210 \mathrm{~nm}$ is ascribed

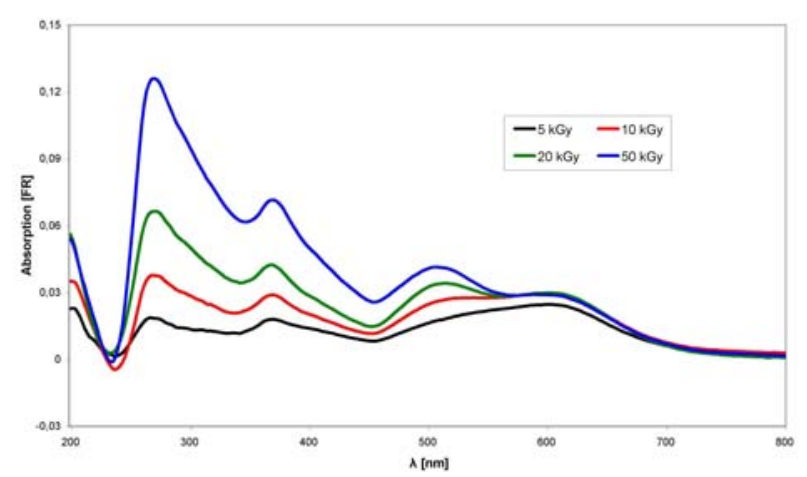

Fig. 1. DRS spectra for different dose of gamma radiation. The samples were irradiated in air. to peroxide groups. Bands at $295-320 \mathrm{~nm}$ are ascribed to CO groups at the end of chains (products of degradation) and peaks in the range of 245 are ascribed to carboxyl groups in the middle of polymer chains. The height of each peak (270 and $368 \mathrm{~nm}$ ) increases almost linearly with the radiation dose absorbed (Fig. 2).

Radiolysis of newsprint that contains lignin is much more difficult. Clearly, lower is the efficiency of hydrogen evolution and yield of oxygen uptake (Table 1). Also DRS spectra bands corresponding to oxidation products are much less intense than for newsprint for almost pure cellulose (Fig. 3). Demonstrates the protective effect of lignin radiolysis process paper.

DRS spectra of paper obtained directly after irradiation and after irradiation and aging points to the greater degradation of the samples subjected to the irradiation treatment. Although for pure cellulose, the effect was visible, for newsprint, there was little effect (Fig. 4).

\section{Conclusions}

Both gas chromatography and DRS provide valuable information about the degradation of paper.

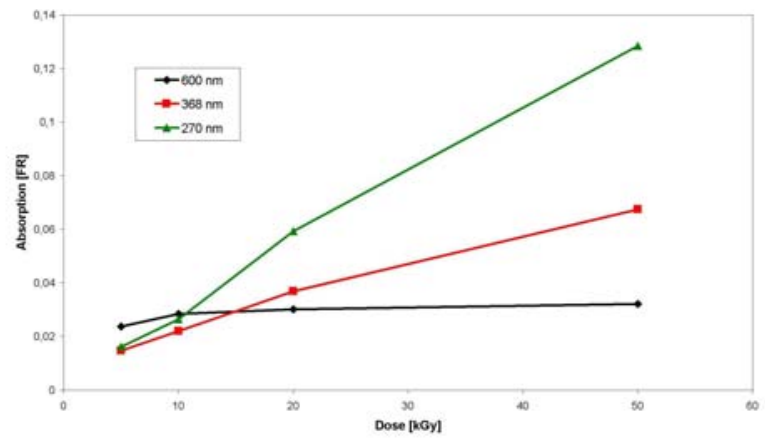

Fig. 2. Height of the peaks in the spectrum of DRS for different length of the wave.

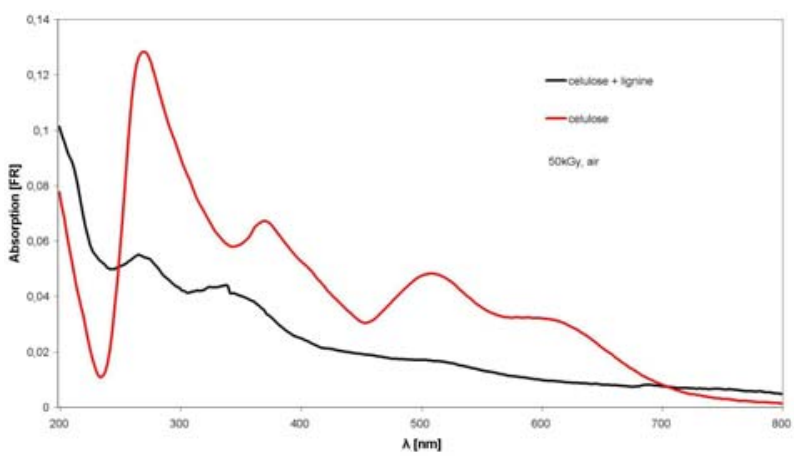

Fig. 3. The protective effect of lignin in cellulose radiolysis. 


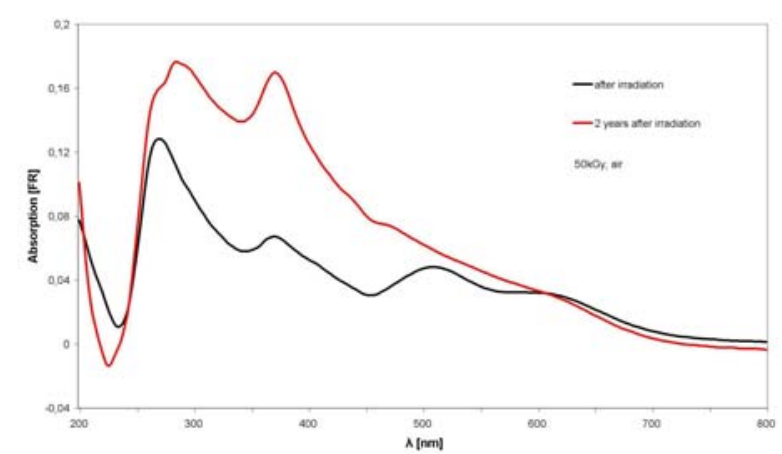

Fig. 4. Irradiation slightly accelerates the aging of the paper.

DRS was first used to study the effects of ionizing radiation on the paper.

It was confirmed experimentally that it is much preferred from the viewpoint of degradation is to use high dose rate. In particular, if allowed by the extent of radiation, DRS is better than the use of EB of gamma radiation with low power.

Using the DRS can assess the scale of the protective effect of lignin in cellulose radiolysis. The protective effect is observed both during irradiation and postradiation oxidation. The second is the effect of reducing the number of macroradicals at the primary stage radiolysis.

\section{References}

1. Area, M. C., Calvo, A. M., Felissia, E. F., Docters, A., \& Miranda, M. V. (2014). Influence of dose and dose rate on the physical properties of commercial papers commonly used in libraries and archives. Radiat. Phys. Chem., 96, 217-222. DOI: 10.1016/j. radphyschem.2013.10.004.

2. Cortella, L., Tran, K. Q., Głuszewski, W. J., Moise, I. V., \& Ponta, C. C. (2011). Nuclear techniques for preservation of cultural heritage artefacts. In IAEA Technical Cooperation Project - RER 8015: Using Nuclear Techniques for the Characterization and Preservation of Cultural Heritage Artefacts in the European Region. Vienna: International Atomic Energy Agency.

3. Moise, I. V., Virgolici, M., Negut, C. D., Manea, M., Alexandru, M., Trandafir, L., Zorila, F. L., Talasman, C. M., Manea, D., Nisipeanu, S., Haiducu, M., \& Balan, Z. (2012). Establishing the irradiation dose for paper decontamination. Radiat. Phys. Chem., 81(8), 1045-1050. DOI: 10.1016/j.radphyschem.2011.11.063.

4. Bankole, O. M. (2010). A review of biological deterioration of library materials and possible control strategies in the tropics. Library Rev., 59(6), 414-429. DOI: $10.1108 / 00242531011053931$.

5. Sterflinger, K., \& Pinzari, F. (2012). The revenge of time: fungal deterioration of cultural heritage with particular reference to books, paper and parchment. Environ. Microbiol., 14(3), 559-566. DOI: 10.1111/j.1462-2920.2011.02584.x.

6. Area, M. C., \& Cheradame, H. (2011). Paper aging and degradation: recent findings and research methods. BioResources, 6(4), 5307-5337.

7. Bansa, H. (1981). The conservation of library collections in tropical and sub-tropical condition: the problem of increased dangers of damage and decay in areas of high temperature and humidity. IFLA J., 7(3), 264 -267. DOI: 10.1177/034003528100700308.

8. Choi, J., Chung, Y. J., Kang, D. I., Lee, K. S., \& Lee, J. -W. (2012). Effect of radiation on disinfection and mechanical properties of Korean traditional paper, Hanji. Radiat. Phys. Chem., 81, 1051-1054. DOI: 10.1016/j.radphyschem.2011.11.019.

9. Da Silva, M., Moraes, A., Nishikawa, M., Gatti, M., Vallim de Alencar, M., Brandao, L., \& Nobrega, A. (2006). Inactivation of fungi from deteriorated paper materials by radiation. Int. Biodeterior. Biodegrad., 57(3), 163-167. DOI: 10.1016/j.ibiod.2006.02.003.

10. Katušin-Ražem, B., Ražem, D., \& Braun, M. (2009). Irradiation treatment for the protection and conservation of cultural heritage artefacts in Croatia. Radiat. Phys. Chem., 78, 729-731. DOI: 10.1016/j.radphyschem.2009.03.048.

11. Magaudda, G. (2004). The recovery of biodeteriorated books and archive documents through gamma irradiation: some considerations on the results achieved. $J$. Cultural Heritage, 5(1), 113-118. DOI: 10.1016/j. culher.2006.02.007.

12. Bouchard, J., Méthot, M., \& Jordan, B. (2006). The effects of ionizing radiation on the cellulose of woodfree paper. Cellulose, 13(5), 601-610. DOI: 10.1007/ s10570-005-9033-0.

13. D'Almeida, M. L. O., Barbosa, P. D. S. M., Boaratti, M. F. G., \& Borrely, S. I. (2009). Radiation effects on the integrity of paper. Radiat. Phys. Chem., 78(7/8), 489-492. DOI: 10.1016/j.radphyschem.2013.10.004.

14. Martin, D., Craciun, G., Manaila, E., Ighigeanu, D., Oproiu, C., \& Iacob, N. (2005). In Synergistic effects obtained by combined electron beam and microwave irradiation (pp. 1-8). (IAEA-CN-115-48). Vienna: International Atomic Energy Agency.

15. Głuszewski, W., Zagórski, Z. P., \& Rajkiewicz, M. (2014). Protective effects in radiation modification of elastomers. Radiat. Phys. Chem., 105, 36-39. DOI: 10.1016/j.radphyschem.2014.06.024.

16. Ivanova, I. A., \& Popova, D. Y. (2014). Pigmented yeasts survived $20 \mathrm{kGy}$ gamma irradiation. Bulg. J. Agric. Sci., 20(Suppl. 1), 31-36. 